\title{
Produção rural e segurança alimentar no Brasil
}

Udo Strassburg

Doutorando no Programa Pós-Graduação em Desenvolvimento Regional e Agronegócio da Universidade Estadual do Oeste do Paraná (Unioeste)

Nilton Marques de Oliveira

Doutorando no Programa Pós-Graduação em Desenvolvimento Regional e Agronegócio da Universidade Estadual do Oeste do Paraná (Unioeste)

Isabela Barchet

Doutoranda no Programa Pós-Graduação em Desenvolvimento Regional e Agronegócio da Universidade Estadual do Oeste do Paraná (Unioeste)

Camili Dal Pai

Doutoranda no Programa Pós-Graduação em Desenvolvimento Regional e Agronegócio da Universidade Estadual do Oeste do Paraná (Unioeste)

Paulo César da Silva Ilha

Doutoranda no Programa Pós-Graduação em Desenvolvimento Regional e Agronegócio da Universidade Estadual do Oeste do Paraná (Unioeste)

Pery Francisco Assis Shikida

Programa Pós-Graduação em Desenvolvimento Regional e Agronegócio da Universidade Estadual do Oeste do Paraná (Unioeste)

Recebido: 10/04/2015 Versão revisada (entregue): 23/07/2015 Aprovado: 24/08/2015

\begin{abstract}
Resumo
$\mathrm{O}$ artigo tem como objetivo realizar uma abordagem sobre segurança alimentar e desenvolvimento rural de 1964 a 2011, fundamentado nas contribuições de pensadores brasileiros que analisam essa temática. Para tanto, recorreu-se a um ferramental metodológico exploratório e a literatura especializada. O Brasil é uma referência mundial na produção de alimentos. Porém, parcela significativa da população não tem acesso a uma alimentação adequada que possa caracterizar uma condição de segurança alimentar. Sugere-se que esse cenário decorre, principalmente, de aspectos sociais, entre os quais se destaca a desigual distribuição de renda. Políticas públicas foram implantadas no período analisado de modo a minimizar essa condição, destacando-se o Programa Fome Zero. Contudo, verifica-se que é preciso criar condições de inserção social e econômica para a população por meio do incentivo a novas atividades locais, que contribuam também para o desenvolvimento rural.
\end{abstract}

Palavras-chave | Alimentos; Brasil; pluriatividade; produção rural; segurança alimentar.

Código JEL | L66; Q18; Q56. 


\title{
RURAL PRODUCTION AND FOOD SECURITY IN BRAZIL
}

\begin{abstract}
This paper aims at making an approach on food safety and rural development between 1964 and 2011, based on the contributions of Brazilian thinkers who analyze those themes. Thus, an exploratory and bibliographic methodological set was used. Being considered a world reference in food production, Brazil faces a paradox, even with a growing production in agriculture, it is possible to notice that a significant part of the population does not have access to appropriate feeding which might characterize a food safety condition. Such contradiction suggests that the scenario results, from social aspects, of which is stood out the unequal income distribution. Several public policies were implanted along the studied period in order to reduce that condition, for instance Fome Zero Program. However, it is verified that more important than redistributing income, it is necessary to create social and economic inclusion conditions to the population, through incentives to new rural and non-rural activities respecting the local aspects and so contributing to rural development.
\end{abstract}

Keywords | Brazil; food; food security; pluriactivity; rural production.

JEL-Code | L66; Q18; Q56.

\section{LA PRODUCCIÓN RURAL Y LA SEGURIDAD ALIMENTARIA EN BRASIL}

\section{Resumen}

El artículo tiene como objetivo realizar un abordaje sobre la seguridad alimentaria y el desarrollo rural, de 1964 a 2011, fundamentado en las contribuciones de pensadores brasileños que analizan esa temática. Para ello, se utilizó un aparato metodológico exploratorio y la literatura. El Brasil es una referencia mundial en la producción de alimentos, pero parte significativa de la población no tiene acceso a una alimentación adecuada que pueda caracterizar una condición de seguridad alimentaria. Se sugiere que ese escenario se debe principalmente a aspectos sociales, entre los que se destaca la distribución de renta desigual. Políticas públicas fueron implantadas en el periodo analizado a fin de minimizar esa condición, destacándose el Programa Fome Zero. Sin embargo, se verifica que más importante que distribuir renta es crear condiciones de inserción social y económica para la población, por medio del incentivo a nuevas actividades locales y que contribuyan también para el desarrollo rural.

Palabras-clave | Alimentación; Brasil; pluriactividad; producción rural; seguridad alimentaria.

Código JEL | L66; Q18; Q56.

\section{Introdução}

Considera-se que há segurança alimentar para uma população se todas as pessoas têm, permanentemente, acesso a alimentos suficientes para uma vida ativa e saudável. Nesse contexto, o conceito de segurança alimentar é limitado, pois o problema da insegurança alimentar ou da fome no Brasil radica-se na pobreza de grande parte da população e não na limitação da oferta de alimentos 
(HOFFMANN, 1995; HOFFMANN, 2008; HOFFMANN, KAGEYAMA, 2007).

Com o advento da Revolução Verde, embrionária no Brasil já nos anos 1940, o país passou por um processo de expansão da produção agrícola possibilitado pela ampliação dos investimentos em tecnologia e ocupação de novas áreas destinadas ao cultivo, iniciando um sistema que o transformaria em referência mundial na produção agropecuária. Contudo, mesmo diante da crescente produção e acumulação de riquezas provenientes da agricultura, verifica-se que parcela significativa da população ainda não tem acesso a uma alimentação saudável ou até mesmo à ingestão mínima de nutrientes necessários para garantir o seu bem-estar, sugerindo que a questão da segurança alimentar de 1964 a 2011 decorre da distribuição de renda desigual, sendo um importante ponto de discussão do Estado (BELIK, 2003; SZMRECSÁNYI, RAMOS, 1994).

No cenário brasileiro houve um avanço significativo decorrente da ação conjunta entre o poder público e privado, através de mobilizações e de políticas institucionais visando garantir o acesso à alimentação pelas camadas mais carentes. Frente ao exposto, coloca-se como questão central do estudo a seguinte problemática: as políticas agrícolas adotadas contribuíram para a segurança alimentar brasileira e, consequentemente, para o desenvolvimento rural?

Para tanto, o estudo utiliza-se de um ferramental metodológico exploratório e também uma revisão da literatura (sobre o procedimento metodológico desse artigo ver Richardson (2007) e Flick (2009)), tendo como objetivo central realizar uma abordagem dos principais pensadores sobre a economia rural brasileira com ênfase na segurança alimentar (1964 a 2011). Especificamente, pretende-se contextualizar o ambiente macroeconômico do qual evoluiu a discussão sob o foco dessa pesquisa (seção 2); apresentar as contribuições de alguns pesquisadores nacionais acerca da temática de segurança alimentar (seção 3); apresentar as principais ações e medidas institucionais relacionadas à segurança alimentar implementadas no país (seção 4) e, por fim, discorrer sobre a relação dessas medidas com o desenvolvimento rural brasileiro (seção 5).

Acredita-se que essa análise contribuirá para a compreensão de quais foram as ações e medidas institucionais implementadas que transformaram o Brasil em uma referência na produção de alimentos. Cabe ressaltar que este estudo não tem como pretensão esgotar o tema e a literatura relacionada à segurança alimentar e ao desenvolvimento rural no Brasil.

\section{Notas sobre o ambiente econômico brasileiro (1964-2011)}

O corte temporal adotado neste estudo justifica-se em função de que na década de 1960 emergiu uma discussão acadêmica em torno do fato de a agricultura estar ou 
não cumprindo sua função de fornecedora de alimentos, e de que modo a estrutura fundiária estaria limitando a agropecuária de responder aos estímulos de preços, assim, comprometendo a segurança alimentar do Brasil.

Destacam-se, nesta discussão, as contribuições de Furtado (2007) e Paiva (1976). Furtado (2007) afirmava que a estrutura fundiária impedia a produção de alimentos em grande escala, sendo que a terra era mantida, em boa parte, como reserva de valor e não para fins de produção. Para Paiva (1976), a oferta de alimentos seria elevada mediante a adoção de políticas visando o estímulo à produção.

De 1964 a 1986 acelerou-se o processo de modernização da agricultura brasileira, que foi impulsionada por diversas políticas direcionadas a estimular o crescimento do setor, entre elas a política de expansão da malha rodoviária, políticas específicas de crédito rural, preços mínimos, pesquisa e extensão rural (KAGEYAMA, 1990).

A política de expansão do sistema rodoviário brasileiro, com a construção de novas estradas e a pavimentação de outras já existentes, tinha como objetivo acessar novas regiões, como o Centro-Oeste e o Norte. Essas duas regiões, em especial o Centro-Oeste, constituíram a nova fronteira agrícola a partir dos anos 1970 e assumiria nos anos 1990 a posição de principal produtora de grãos para abastecer o Brasil e outros países (FAVARETO, 2009).

A política de crédito rural, implantada pelo Sistema Nacional de Crédito Rural (SNCR) instituído a partir de 1965, ofereceu volumes crescentes de empréstimos durante a década de 1970 com taxas de juros reais negativas. Para Bacha (2012), isso implicava em transferência de recursos de outros setores da economia para a agropecuária.

Com a política de crédito rural subsidiado foi possível expandir e modernizar a agropecuária. Isso porque o recebimento desse crédito implicava compra de insumos modernos (fertilizantes e defensivos) ou de equipamentos (tratores, colheitadeiras, arados). Desse modo, a agropecuária, ao se modernizar, também estimulou a produção nacional de equipamentos e insumos agropecuários (KAGEYAMA, 1990). O SNCR não beneficiou somente os grandes produtores, mas também favoreceu de forma modesta a agricultura familiar no que tange $\mathrm{o}$ acesso ao crédito, ao insumo e a novas tecnologias.

Na primeira metade da década de 1970 foi criada a Empresa Brasileira de Pesquisa Agropecuária (Embrapa) e a Empresa Brasileira de Assistência e Extensão Rural (Embrater), que eram órgãos federais responsáveis por coordenar as atividades de pesquisa e extensão rural, respectivamente. Os resultados obtidos por pesquisas da Embrapa foram essenciais para viabilizar a expansão da agropecuária ocorrida no Cerrado brasileiro. $\mathrm{O}$ aumento da mecanização e do uso de fertilizantes, associado com os resultados de pesquisas agropecuárias, implicou grande crescimento da produtividade das lavouras e, consequentemente, no aumento da produção de alimentos no Brasil (PEREIRA et al., 2012). 
Outro elemento que fomentou a produção de alimentos no país foi a Política de Garantia de Preços Mínimos (PGPM), com forte atuação entre 1975 e 1979. Foram criados estímulos creditícios e fiscais para incrementar as exportações de produtos in natura e agroindustrializados (BACHA, 2012).

Até 1986 as políticas macroeconômicas, notadamente as políticas agrícolas, promoveram estímulos para o aumento da produção de alimentos, contribuindo para a segurança alimentar e o processo de desenvolvimento socioeconômico do Brasil. Contudo, a partir de 1987, em função do ambiente macroeconômico, foram adotadas medidas contracionistas que implicaram, entre outros aspectos, uma significativa redução de estímulos para a atividade agropecuária. A redução do volume de crédito levou os agricultores a utilizarem recursos próprios ou de terceiros, além de outras formas de comercialização (GASQUES et al, 2010).

O período inflacionário que vigorou no país de 1987 a 1994 e as crises do balanço de pagamentos até o final da década de 1990 levaram à adoção de diferentes regimes cambiais, que prejudicaram o desempenho da agropecuária brasileira, reduzindo sua receita. Há de se considerar que, nesse mesmo período, a economia passou por diferentes planos de estabilização econômica, o que provocou a redução do poder aquisitivo da população, restringindo o acesso aos produtos alimentares (VASCONCELLOS et al., 1999).

Com a criação do Plano Real (1994), passou a vigorar um sistema de câmbio flexível. Entre 1995 e 1998, houve o sistema de "minibandas cambiais", implicando grande valorização da moeda nacional, desfavorecendo as exportações. As crises financeiras e a falta de reserva do Banco Central restringiram a intervenção desse órgão no mercado de divisas, provocando a desvalorização do Real, favorecendo as exportações. Entre 2003 e 2008, ocorreu uma persistente valorização do Real. A estabilidade monetária da economia brasileira atraiu capital estrangeiro e, por outro lado, prejudicou as exportações (BACHA, 2012).

Em suma, pode-se afirmar que na década de 2000, apesar da redução significativa de estímulos à agropecuária (redução da taxa de câmbio real, aumento do valor real do salário-mínimo, escassez do crédito rural, diminuição da cobertura da Política de Preços Mínimos e redução de gastos públicos com a agropecuária), essa atividade expandiu-se no Brasil, principalmente, em função do menor uso de área e mão de obra. Isso só foi possível devido ao aumento da produtividade por meio do uso de novas tecnologias e pela qualificação dos produtores rurais, contribuindo para que o país alcançasse a posição de um dos maiores produtores de alimentos do mundo (GASQUES et al., 2010; JANK et al., 2005). 


\section{As transformações da agricultura e o debate sobre a segurança alimentar}

Nesta seção serão apresentadas algumas discussões sobre as transformações da agricultura, bem como o debate acerca da segurança alimentar no Brasil.

Há de se considerar que o setor agropecuário exerce importantes funções no processo de desenvolvimento econômico de um país. Segundo Paiva (1976), essas funções seriam: aumentar a oferta de alimentos e matérias-primas a preços menores; elevar a renda líquida do setor, de modo que se constitua num importante mercado consumidor dos produtos do setor não agrícola; aumentar o número de emprego na agricultura e o acesso à terra; melhorar a distribuição de renda no setor; garantir condições satisfatórias de vida familiar e social aos agricultores, proprietários ou não. Bacha (2012) atenta para a ampliação dessas funções ao considerar que a agropecuária contribui para fornecer divisas para a compra de insumos e bens de capitais necessários ao desenvolvimento de atividades econômicas; liberar mão de obra para o crescimento e diversificação de atividades não agrícolas na economia e fornecer capitais para a expansão do setor não agrícola.

Paiva (1976) indaga como cumprir essas funções e evitar os possíveis conflitos que existem entre elas como, por exemplo, o de se buscar simultaneamente redução de preços e aumento de retorno líquido dos agricultores. A resposta apontada é que esses objetivos seriam atingidos com a modernização das atividades agrícolas.

Kageyama (1990) descreve o novo padrão agrícola brasileiro que surge a partir de 1960 com a consolidação do processo de modernização da agricultura e início do processo de industrialização da agricultura. A partir destas transformações, constituem-se, no período pós-1975, o que a autora denomina de complexos agroindustriais (CAI's).

A partir de meados dos anos 1960, o processo de modernização atinge uma fase mais avançada, a da industrialização da agricultura. Esse processo não se restringe à utilização de insumos industriais na produção agrícola, pois, nessa fase, ocorre a reunificação agricultura-indústria num patamar mais elevado do que o do simples consumo de bens industriais pela agricultura. É o momento em que a indústria passa a comandar a direção, as formas e o ritmo da mudança na base técnica agrícola (KAGEYAMA, 1990; PAIVA, 1976).

Para Kageyama (1990) e Kageyama; Leone (2002), três transformações básicas diferenciam a modernização da agricultura do processo de industrialização da agricultura. Primeiro, a partir do momento em que a agricultura se industrializa, ocorre uma mudança nas relações de trabalho. Nessa fase, a relação de trabalho é basicamente uma relação de trabalho coletivo (cooperativo). Na segunda mudança as atividades passam a ser mecanizadas. A terceira transformação é a 
internalização dos setores produtores de insumos, máquinas e equipamentos para a agricultura.

Isso posto, fica evidente que a principal modificação na dinâmica da agricultura brasileira consistiu em um processo histórico de passagem do chamado complexo rural para a dinâmica comandada pelos complexos agroindustriais (CAI's). Nesse processo constata-se a emergência das atividades agroindustriais, a especialização da produção agrícola e o crescimento do mercado interno como elemento de alocação dos recursos produtivos no setor agropecuário (KAGEYAMA; SILVA, 1983).

Destaca-se que a participação e a intervenção estatal não se restringiu apenas às variáveis diretamente ligadas ao setor agrícola (tais como crédito agrícola, preços mínimos, seguros agrícolas, assistência técnica e apoio à pesquisa), mas envolveu também as políticas monetária, fiscal, cambial e outros mecanismos que impactaram nas decisões dos agentes envolvidos na produção agrícola (SZMRECSÁNYI, 1996).

As modificações no padrão e na dinâmica da agricultura brasileira apresentaram consequências importantes para o desempenho de suas funções básicas, entre elas a oferta de alimentos para o país. As ações adotadas enfatizaram a expansão da produção como forma de diminuir o preço interno dos alimentos, e por trás dessa ação estava o diagnóstico da insuficiência da oferta de produtos agrícolas nas décadas de 1960 e 1970 (KAGEYAMA, 1990). Desse modo, tanto a expansão regular da oferta de alimentos como a redução real dos preços internos destes passaram não apenas por uma política de fomento a produção, mas também por uma política industrial para a agricultura com redução dos custos dos insumos, máquinas e do processamento industrial de produtos agrícolas (JANK et al., 2005).

O fortalecimento de agricultores de pequenas propriedades é fundamental para condicionar um ambiente favorável que propicie a segurança alimentar. A quantidade de pequenas propriedades é muito grande no Brasil e estas necessitam de um olhar especial. Segundo IBGE (2013), em 2006 havia no país 47\% dos estabelecimentos agropecuários com menos de 100 hectares; dada a limitação de área, não há como remunerar melhor a família sem o aumento da produtividade, conforme argumentava Alves (2001).

A definição de agricultura familiar, de acordo com a legislação brasileira (Lei 11.326/2006), caracteriza que o agricultor familiar rural é aquele que não detém área maior que quatro módulos fiscais; utiliza predominantemente mão de obra da própria família nas atividades econômicas do seu estabelecimento ou empreendimento; tem renda familiar predominantemente originada de atividades econômicas vinculadas ao próprio estabelecimento ou empreendimento e dirige seus negócios com sua família. 
No entanto, como ressaltam Alves et al. (2006), são numerosos os pequenos estabelecimentos que apresentam renda líquida negativa demandando recursos de fontes externas, de crédito ou de venda de patrimônio para cobrir este déficit, descapitalizando assim a família do agricultor. Por outro lado, registram-se casos em que a renda líquida é não negativa, nos quais ganha destaque a forma de gestão do seu negócio agrícola.

Para suplantar esta discrepância é necessário repensar a agricultura familiar como um setor econômico tão importante quanto a agricultura comercial, superando o problema da viabilidade econômica que restringe o acesso às políticas de fomento à produção. Para garantir este acesso, algumas exigências fundamentais devem ser observadas. Primeiramente, permitir a inserção do produtor ao mercado competitivo via uso de tecnologias modernas, ditas produtivistas, mesmo que adaptadas. Em segundo lugar, superar o paradigma de que a maior parcela da renda das famílias seja proveniente da atividade produtiva agropecuária, como também pode ser complementada via transferência de renda de programas de políticas públicas, como: aposentadoria rural, pensão, benefícios sociais e bolsa família. Decorre desta concepção a redefinição da atividade agrícola e, por conseguinte, da própria profissão do agricultor (MALUF, 2003).

Não obstante, há questões que não podem ser dissociadas, destacando que a "tecnologia, o crédito rural, a extensão e a administração rural são inseparáveis no trato dos problemas da agricultura familiar." (ALVES, 2006a, p. 3). Apesar de fundamentais, essas questões ainda representam entraves aos pequenos produtores, e devem ser consideradas pelos órgãos governamentais, a fim de elevar a produtividade das pequenas propriedades gerando um excedente agrícola e contribuindo para que o país alcance a autossuficiência da produção interna garantindo o progresso da agricultura familiar (ALVES, 2001).

Como sugerido, essa nova conotação avança além de assuntos meramente produtivos, passando a vislumbrar o indivíduo como principal agente em questão, além de aspectos ambientais e de alocação eficiente dos recursos (ALVES, 2006a; FAVARETO, 2010). Para Schneider et al. (2011), o desenvolvimento rural é um processo complexo e controverso em permanente evolução, ora evoluindo de forma lenta, ora através de mudanças abruptas. Conforme Favareto (2010), esse processo caracteriza a nova ruralidade que combina tanto a visão agrícola e produtivista como a visão territorial do desenvolvimento rural, sendo esta imprescindível.

Essa mudança é decorrente de alterações políticas, econômicas e ideológicas. Diversos autores consideram que o desenvolvimento rural só pode ser obtido com a superação de elementos estritamente produtivos e, por muitas vezes, não sustentáveis e que devem envolver a correção das desigualdades espaciais por meio da redistribuição da riqueza e da renda (FAVARETO, 2010; SCHNEIDER, 2010). 
No Brasil essa discussão avançou a partir dos anos 1990 com a ampliação dos movimentos sociais e sindicais, que levaram o Estado a implantar políticas públicas com atenção aos agricultores familiares, à reforma agrária e à segurança alimentar. Por outro lado, as medidas econômicas adotadas para o combate à inflação e à instabilidade macroeconômica também contribuíram significativamente para a transformação da discussão sobre o rural, bem como as transformações de ordem ideológica com ampliação do debate ambiental (FAVARETO, 2010).

Belik (2012) afirma que o debate sobre segurança alimentar no Brasil é relativamente recente, muito embora a questão alimentar seja discutida no país desde o período colonial. $\mathrm{Na}$ verdade, o direito à alimentação foi incluído entre os direitos sociais fixados no artigo $6^{\circ}$ da Constituição Federal brasileira apenas no início de 2010. Takagi (2006) expõe que as discussões e políticas implantadas entre o período colonial e a década de 1970 tinham por objetivo solucionar o problema da carestia de alimentos, além de dinamizar a economia e gerar divisas ao país. Tratavam-se de políticas de abastecimento e/ou estruturalistas, com foco na escassez, na estabilização dos preços e escoamento da produção de alimentos, ideário que perdurou até os anos 1990.

A segurança alimentar engloba o objetivo de garantir a todas as condições de acesso suficiente, regular e a baixos custos aos alimentos básicos, porém estudos realizados no Brasil desde a década de 1970 mostram clara relação entre a situação social e econômica e as más condições de alimentação. Destarte, Maluf (1995) defende que projetos relacionados à segurança alimentar deveriam combinar ações assistenciais-compensatórias frente a questões emergenciais como a fome, com políticas de caráter estruturante visando assegurar o acesso aos alimentos sem comprometer parcela substancial da renda familiar; disponibilizar alimentos de qualidade, originados de formas produtivas eficientes, porém, não excludentes e sustentáveis e divulgar informações ao consumidor sobre práticas alimentares saudáveis e possíveis riscos a saúde, mediados pelo alimento.

Assim, a equidade social com ênfase na questão da renda, fome e desnutrição é um elemento associado à segurança alimentar que precisa ser discutido. Um país pode ter uma população desnutrida, sem que necessariamente seja faminta, pois, considera-se que a desnutrição está associada "não apenas a falta de ingestão de alimentos, mas também a diversificação e a adequação nutricional da dieta, conhecimentos básicos de higiene, condição salubre de moradia, cuidados de saúde etc." (BELIK, 2003, p. 15). E devem ainda envolver dimensões como promoção de atividade econômica, oferta de alimentos típicos com qualidade e ao estímulo à diversidade cultural, todas essenciais para implementação de uma estratégia de desenvolvimento com segurança alimentar (HOFFMANN, 2008; MALUF et al., 1996; MALUF, 2000). 
Pode-se dizer que, historicamente, as ações de combate à escassez de alimentos para viabilizar a segurança alimentar podem ser entendidas como um conjunto de políticas institucionais articuladas em incentivos à produção agrícola e distribuição de renda (BELIK, 2003; HOFFMANN, KAGEYAMA, 2007; MALUF, 1999). Portanto, a segurança alimentar deve ser parte integrante das questões econômicas e de políticas públicas, como elemento essencial de um país que pretende ser desenvolvido, de tal forma que se possa tomá-la como componente estratégico do padrão de desenvolvimento (MALUF, 1995). Todavia, esta estratégia demanda um planejamento de longo prazo das diversas questões que envolvam uma vida ativa e saudável, o que, infelizmente, não é uma prática comumente utilizada em países como o Brasil (HOFFMANN, 1995).

Mais recentemente, a discussão sobre segurança alimentar tem evoluído para temas como o de soberania alimentar, que se refere à autonomia na produção de alimentos dos países, menor dependência do mercado externo, menor vulnerabilidade às flutuações nos preços internacionais, envolvendo ainda a geração de empregos e promoção da cultura e dos hábitos alimentares das regiões (BELIK, 2003).

A próxima seção discute a evolução e as políticas de segurança alimentar no Brasil.

\section{A evolução e as políticas de segurança alimentar no Brasil}

Conforme Belik (2003), entre as décadas de 1930 e 1960 são registrados mecanismos de forte intervenção, período em que se consolidou uma política de abastecimento alimentar fundamentada naqueles moldes anteriores a esse período, com foco no aumento da oferta e no controle de preços.

A partir da década de 1970, ainda sob forte intervenção, é criado o Instituto Nacional de Alimentação e Nutrição (INAN), vinculado ao Ministério da Saúde, representando uma nova estrutura com a missão de administrar os Programas Nacionais de Alimentação e Nutrição. Soma-se a essa ação a implantação de armazéns e centrais de abastecimentos atacadistas e varejistas (BELIK, 2012; TAKAGI, 2006). Outro fato relevante na década de 1970 foi a efetivação do International Covenant on Economic, Social and Cultural Rights, que culminou em um pacto entre os Membros da Organização das Nações Unidas (ONU) estabelecendo compromissos econômicos, sociais e culturais, entre os quais, o de assegurar o chamado "direito fundamental de estar livre da fome" (BELIK, 2012; LAFER, 1995).

A década de 1980 é marcada pela promulgação da Assembleia Constituinte, pela hiperinflação e pelos programas de congelamento de ativos que agravariam ainda mais a situação nutricional das famílias. Nesse período foi realizada a I Conferência Nacional de Alimentação e Nutrição e a $8^{a}$ Conferência Nacional de 
Saúde, envolvendo a participação de representantes da sociedade civil. Entretanto, mesmo diante de tais esforços, o direito à alimentação ficou de fora do texto final da Constituição Federal de 1988, sendo incorporado apenas em 2010 com a Emenda Constitucional no 64 (BELIK, 2012).

Outros programas que se destacaram nos anos 1980 foram os voltados à assistência em massa, como aqueles direcionados à alimentação escolar e o Programa Nacional do Leite para Crianças Carentes (PNLCC), popularmente conhecido como "tickets do Sarney". Apesar de controverso, o programa apresentou resultados favoráveis em termos de nutrição e apoio à pecuária local (BELIK, 2012).

Os anos 1990 foram marcados por uma sucessão de contrarreformas liberais, rumo à desestruturação do Estado de Bem-Estar Social (Welfare State). No início da década quase todos os programas de alimentação criados anteriormente estavam paralisados, foram feitos significativos cortes orçamentários, e a população enfrentou sucessivas crises de fome desencadeadas pelas secas no Nordeste, crise inflacionária e desemprego (CHADDAD, JANK, 2006; TAKAGI, 2006).

Nesse cenário emerge intensa mobilização nacional, com campanhas como a "Ação da Cidadania contra a Fome, a Miséria e pela Vida" que, juntamente com a iniciativa do Governo Paralelo ${ }^{1}$ ao elaborar e apresentar ao Governo Federal uma Política Nacional de Segurança Alimentar, serviram como tentativa de implantação do primeiro plano de segurança alimentar no país (SCHNEIDER et al., 2011).

Belik (2012) expõe que ainda nos anos 1990 difundiram-se novas práticas no Brasil e no mundo que influenciariam diretamente o rumo dos programas sociais na década seguinte no país. $O$ autor destaca duas iniciativas: os programas municipais de transferência de renda para combater a pobreza e o programa integrado de produção e consumo de alimentos iniciado pela Prefeitura de Belo Horizonte (MG), que centralizava atividades através da regulação, intervenção compensatória e educação e transmissão de práticas alimentares (BELIK, 2012).

No âmbito de políticas macroeconômicas, em 1995 foi instituído o Programa Nacional de Fortalecimento da Agricultura Familiar (PRONAF). De acordo com Graziano da Silva (2002), o PRONAF destina-se a promover o desenvolvimento sustentável do meio rural, a partir do aumento da capacidade produtiva, geração de empregos, elevação da renda e melhoria da qualidade de vida dos agricultores familiares.

\footnotetext{
${ }^{1}$ Conforme aponta Norder (1998), o Governo Paralelo correspondeu a uma ação do Partido dos Trabalhadores (PT) implementada no período da transição democrática brasileira, na qual, mesmo ocupando a oposição política, eram apresentadas alternativas e propostas de políticas públicas ao então Presidente da República eleito diretamente.
} 
O Programa foi uma das iniciativas mais importantes ocorridas na política agrícola nos anos 1990, uma vez que consolidou as instituições, normas e procedimentos em condições favoráveis, disponibilizando o crédito rural para o pequeno produtor (BELIK, 1999; CHADDAD, JANK, 2006; KAGEYAMA, 2003a). Outra política criada para dar um suporte especial à agricultura familiar, estando também relacionada à segurança alimentar, é o Programa de Aquisição de Alimentos (PAA). De acordo com Maluf (1999), o PAA contempla tanto as demandas de acesso aos alimentos da população em situação de insegurança alimentar como as necessidades dos agricultores familiares de conseguirem mercados para seus produtos, propiciando uma segurança para os pequenos agricultores, pois assegura preço, novos mercados e rendas alternativas.

Apesar de uma ampla discussão, Belik (2004) ressalta que a política de segurança alimentar de fato é implantada somente em 2002 com o Programa Fome Zero, no qual buscou-se desenvolver um modelo que não se resumisse a ações emergenciais ou assistenciais, de mera transferência de renda, mas desenvolver uma política estruturante promovendo a inclusão social da população que passam fome, além de viabilizar a soberania alimentar do país. Assim sendo, o Programa apresenta estratégias agregadas em quatro eixos articuladores: acesso aos alimentos, fortalecimento da agricultura familiar, geração de renda e articulação, mobilização e controle social.

Conforme Graziano da Silva et al. (2010), o problema da fome não é mais a produção de alimentos insuficiente, mas a falta de renda para adquiri-los em quantidade permanente e qualidade adequada. Além disso, existe um círculo vicioso da fome, difícil de ser superado apenas com políticas compensatórias ou de transferências de renda (HOFFMANN, 2006).

Este círculo é retroalimentado, por um lado, pelos problemas estruturais do país, de falta de emprego, salários baixos e concentração de renda; por outro, pela falta de políticas agrícolas e aumentos dos preços dos alimentos. Desse modo, é necessário associar o objetivo da política de segurança alimentar com estratégias de desenvolvimento econômico e social que garantam a equidade e inclusão social (GRAZIANO DA SILVA et al., 2010).

Belik (2003, p. 18) ressalta que "pela primeira vez, com o Fome Zero, poderemos ter no Brasil uma lógica em que a política social é capaz de alavancar o desenvolvimento econômico, e não o reverso, como tem sido ao longo da nossa história". Cumpre destacar que as raízes desse modelo são antigas e fixadas no período de transição democrática, entre 1985 e 1989, sendo que em 1989 o Governo Paralelo avançou na discussão com a preocupação de se complementar as políticas agrícolas e agrárias voltadas para a oferta, e também quanto à criação de políticas de acesso aos alimentos.

Belik (2012) aponta que o Programa Fome Zero opera em três frentes: estrutural, específica para alimentação e local. A primeira envolve medidas voltadas à 
transformação das condições de vida da população (geração de renda e emprego, intensificação da reforma agrária, incentivo à agricultura familiar, etc.). A segunda frente visa aumentar a oferta e o acesso da população aos alimentos e aspectos ligados à qualidade (doações de cestas básicas emergenciais, manutenção de estoques de segurança, segurança e qualidade dos alimentos, etc.). Por fim, a terceira frente está relacionada a questões específicas de cada realidade seja ela rural ou urbana, ou ainda, se em um contexto de grandes, médias ou pequenas cidades.

Em 2011, o Fome Zero beneficiou 13,3 milhões de famílias e contabilizou um montante de US\$10,3 bilhões, tornou-se mundialmente conhecido como um exemplo de programa de combate à fome e desigualdade (BELIK, 2012). Assim sendo, o Programa converge para a contemplação mais ampla do termo "segurança alimentar". Para Bosi (2010), seria uma definição segundo a qual a segurança alimentar e, também, nutricional consiste em garantir a todos condições de acesso a alimentos básicos, seguros, de qualidade e em quantidade suficiente, de modo permanente e sem comprometer o acesso a outras necessidades essenciais. Indiscutivelmente, assim definida, a segurança alimentar corresponde à um conceito de grande amplitude e que se inter-relaciona com diversas outras áreas.

Nesse sentido, torna-se necessário discutir outros aspectos que viabilizam a segurança alimentar. Nesse artigo discute-se, mesmo que de forma breve, como as ações destinadas a promover o desenvolvimento territorial rural, e, mais especificamente, a agricultura familiar, contribuíram ao longo dos anos para a questão da segurança alimentar. Conforme Monteiro; Castro (2009), para alcançar e manter um patamar nutricional adequado para um ser humano, opções alimentares saudáveis precisam ser simultaneamente incentivadas, apoiadas e protegidas. O apoio a opções saudáveis de alimentação dependerá essencialmente de políticas fiscais e de abastecimento que aumentem o acesso da população a alimentos frescos ou minimamente processados. Nesse âmbito, a agricultura familiar desempenha um papel primordial.

\section{Para além da segurança alimentar: a abordagem territorial do desenvolvimento rural}

Apesar de amplamente discutido, Favareto (2010) afirma que o desenvolvimento territorial não se caracteriza como uma teoria, mas como uma abordagem moderna de organização do desenvolvimento rural. Ressalta que esse enfoque iniciou-se com a pesquisa coordenada por José Eli da Veiga, que atenta para a dinâmica territorial como um fator que explica o desenvolvimento de algumas regiões, justificado pela alocação dos fatores de produção, características da população, e, ainda, a relação entre espaço rural e urbano local. 
Com efeito, o desenvolvimento é um processo complexo. De acordo com Veiga (2000), o desenvolvimento rural, enquanto um fenômeno concreto, não pode ser dissociado do desenvolvimento urbano. Conforme Kageyama (2008), o desenvolvimento rural de forma específica se refere a uma base territorial, local ou regional, na qual interagem diversos setores produtivos e de apoio, tratando-se de um desenvolvimento multissetorial e ao mesmo tempo multifuncional. $\mathrm{O}$ setor multissetorial compreende diversos setores que vão desde $\mathrm{o}$ artesanato, processamento de produtos naturais, o turismo rural e a conservação ambiental. $\mathrm{O}$ multifuncional compreende a integração mercantil com cidades da própria região; regiões de agricultura familiar consolidada, a pluriatividade das famílias rurais e a existência de recursos territoriais que permitam produzir para mercados específicos (turismo).

Kageyama (2003b; 2004) complementa afirmando que os elementos definidores do rural modificaram-se ao longo do tempo, ganharam novos contornos. Embora a discussão sobre a definição de rural seja inesgotável e unívoca, há certo consenso sobre os seguintes pontos: a) rural não é sinônimo de agrícola e nem tem exclusividade sobre este; b) o rural é multissetorial (pluriatividade) e multifuncional (funções produtiva, ambiental, ecológica, social); c) as áreas rurais têm densidade populacional relativamente baixa; d) não há um isolamento absoluto entre os espaços rurais e as áreas urbanas.

A partir da virada do século passou-se a reavaliar o significado do desenvolvimento rural, seja pela evolução das relações entre o rural e o urbano, seja pela abordagem das dinâmicas territoriais nos processos de desenvolvimento, principalmente no que diz respeito à complementaridade entre os modus operandis da agricultura familiar e comercial, pois a visão territorial somente se verifica a partir da diversificação e ampliação dos interesses dos agentes envolvidos. Enquanto aquela é fundamental para a diversificação do tecido social e econômico das regiões, devendo, portanto, dispor de prioridade nos investimentos públicos, esta é a que cria um horizonte estratégico para a dinamização da vida econômica e social de qualquer território (FAVARETO, 2010).

Com essa percepção, o desenvolvimento rural implica na criação de novos produtos e serviços, associados a novos mercados e tenta reconstruir a agricultura em termos regionais, representando, enfim, uma saída para as limitações e falta de perspectivas intrínsecas ao paradigma da modernização e ao acelerado aumento de escala e industrialização que ele impõe. Em função disso, para Kageyama (2008), o desenvolvimento rural deve ser considerado a partir dos seguintes aspectos: das relações entre agricultura e sociedade; como novo modelo para o setor agrícola, com particular atenção ao local e ao regional; e como as novas formas de alocação do trabalho familiar, especialmente a pluriatividade.

A partir das definições apresentadas, pode-se almejar a ideia de que o desenvolvimento rural deve combinar o aspecto econômico (aumento do nível e 
estabilidade da renda familiar) e o aspecto social (obtenção de um nível de vida socialmente aceitável), e que sua trajetória principal possa residir na diversificação das atividades que geram renda, o que caracteriza a pluriatividade das famílias rurais (KAGEYAMA, 2004; 2008).

Nessa perspectiva, um projeto que se destaca, a partir dos anos 2000, é o Projeto Rurbano, coordenado por José Graziano da Silva, no qual se verificou a importância da renda não agrícola no orçamento das famílias do campo, mas geradas a partir do espaço rural e não por meio da interação entre campo e cidade (part time job) (FAVARETO, 2010; SCHNEIDER, 1994). Assim, os estudos sobre desenvolvimento rural enfatizaram o "dinamismo dos espaços urbanos e seus desdobramentos na formação das rendas das famílias de agricultores." (FAVARETO, 2010, p. 29).

De acordo com Kageyama (2001), a possibilidade de diversificação das fontes de renda é dada tanto por características das economias locais, como por características internas das famílias. Além disso, o envolvimento em atividades rurais não agrícolas depende essencialmente dos incentivos oferecidos, como a lucratividade e o risco relativo entre atividades agrícolas e não agrícolas, e a capacidade da família para assumir tais atividades.

As famílias agrícolas podem ser motivadas para atividades rurais não agrícolas por fatores de atração, como os maiores retornos dessas atividades, ou por fatores de expulsão da agricultura, como maus resultados de colheitas, ausência de seguro para a safra ou de crédito para consumo, risco da atividade agrícola, entre outros fatores (KAGEYAMA, 1999; KAGEYAMA, HOFFMANN, 2000).

É importante evidenciar que a criação de fontes de renda não agrícola não visa substituir a atividade agrícola, mas pode servir para a sua viabilização. Para Kageyama (2001), a pluriatividade e as rendas não agrícolas são mecanismos que podem viabilizar a sobrevivência da agricultura familiar, contribuir para a fixação da população no meio rural e aliviar a pobreza rural (GRAZIANO DA SILVA, 1999; KAGEYAMA, HOFFMANN, 2000; SCHNEIDER, 2000).

Schneider e Blume (2004) atentam para a superação daquela visão que limita o rural ao atrasado, ao isolamento e à tradição. Favareto (2009) afirma que o âmbito rural não é o mesmo do passado, pois após a segunda metade dos anos 1980 passou por transformações demográficas, econômicas e sociais, integrando-se ao meio urbano, mesmo que de forma contraditória e conflituosa. Dessa forma, adequar as discussões e as instituições a partir dessas mudanças é o grande desafio do desenvolvimento rural (NAVARRO, 2001).

Favareto (2009) destaca seis mudanças principais: 1) A primeira é de ordem demográfica e envolve transformações nas áreas rurais. Essas mudanças são explicadas pelo êxodo rural, pois se estima que $15,6 \%$ da população brasileira habitava o meio rural em 2010, e em 1980 a relação era de 32,3\% (IBGE, 2013); 2) aponta que a importância da agricultura no cenário mundial não se reflete no 
acesso e geração de trabalho. Apesar de a agroindústria representar quase um terço do PIB e gerar uma parcela considerável das exportações nacionais, quando se trata da geração de empregos, esse dinamismo não se verifica; 3) e 4) dizem respeito às transformações de ordem agrária, pois, ainda que a escassez de alimentos não seja um problema no Brasil, as diferenças entre os modos de produção familiar e comercial são socioeconomicamente profundas. 5) cita o território como unidade de planejamento e destaca a importância da descentralização das políticas públicas de assistência social aos agricultores, como o PRONAF; 6) A sexta transformação corresponde ao surgimento de uma economia a partir da nova ruralidade, possibilitada pela ampliação dos programas e serviços sociais, como crédito rural, aposentadoria rural, acesso à energia elétrica e telecomunicações.

Diante do exposto, é necessário desmantelar o falso paradigma que apregoa que os ganhos da agricultura comercial sobrepõem-se aos da familiar, ou ainda, a contradição entre as políticas sociais e as produtivas, mas antes se faz necessário considerar os ganhos potenciais advindos da eficiência distributiva (NAVARRO, 2010; VEIGA, 2006).

Estudos coordenados por Hoffmann e Kageyama (2007) afirmam que as possibilidades de satisfação das necessidades básicas dos indivíduos e das famílias dependem da disponibilidade de certa renda (geralmente proveniente do trabalho), da posse de determinados bens (para assegurar a produção ou para garantir certo nível de conforto) e do acesso a benefícios oferecidos por instituições públicas e privadas.

Schneider (2004) aponta que o desenvolvimento rural emerge da visão de que o modo produtivista estaria em fase de superação, devido à aproximação entre a agricultura e a sociedade, e que por meio da pluriatividade faz com que o meio rural seja visto além da produção de alimentos (GRAZIANO DA SILVA, 2002).

O fenômeno conhecido como pluriatividade descrito, principalmente, pela presença de atividades não agrícolas entre os membros das famílias rurais ou dedicadas à agricultura, caracteriza o que vem sendo chamado de novo rural brasileiro, na esfera das novas relações entre o rural e o urbano (KAGEYAMA, 1999; 2001).

Diante disso, surge a necessidade de se definir um modelo de produção que envolva e concilie essas atividades agrícolas e não agrícolas de forma sustentável, resguardando ecossistemas locais e regionais (VEIGA, 2006). Esse modelo deve ainda redefinir o relacionamento entre os atores locais, a comunidade rural, ampliando a ação pública e o papel das instituições, incorporando, além da agricultura, os indivíduos que ali residem, respeitando sua característica enquanto um agente que é "autônomo, domina tecnologias, toma decisões, controla e gestiona processos, enfim, decide sobre seu modo de viver e trabalhar nos marcos de uma sociedade capitalista." (SCHNEIDER, 2004, p. 97). 
Conforme exposto neste estudo, à medida que o Brasil avança na produção agropecuária, o debate sobre a segurança alimentar deixa de ser associado exclusivamente a questões quantitativas, e passa a ser analisado sob a ótica distributiva, na qual garantir o acesso da população ao alimento é o grande desafio. Essa alteração tem efeitos diretos sobre os estudos do desenvolvimento rural, pois a nova visão o referencia como consequência da elevação da qualidade de vida e incremento da renda no campo, possibilitado pela necessidade de elevação e melhor organização dos recursos (ABRAMOVAY; BEDUSCHI FILHO, 2004).

As novas discussões sobre o desenvolvimento rural apontam para essa premente necessidade, assim, no meio rural a geração alternativa de renda tem sido percebida e incentivada com medidas de diversificação da produção e aproveitamento de atividades não restritas ao cultivo da terra, os elementos não tangíveis, como culinária, cultura, turismo rural, geração de energia, etc. (VEIGA, 2006).

Essas atividades têm um duplo efeito benéfico, a geração de renda e a minimização da pressão ambiental, que associa a expansão da agricultura ao aquecimento global e à perda da biodiversidade. Cabe ressaltar que a pressão ambiental, por sua vez, tem efeito direto sobre a segurança alimentar, uma vez que compromete a produção de alimentos para as gerações futuras (VEIGA, 1996).

Diante da extensão e diversidade do território brasileiro, surge uma economia alternativa fundamentada no aproveitamento, conservação e preservação dos elementos naturais, representando novas vantagens comparativas que elevam a distribuição de renda e melhoria do bem-estar da população do campo (VEIGA, 2002). Logo, a nova política de desenvolvimento rural deve possibilitar a confluência entre preservação ambiental, redução da pobreza e acesso à alimentação (BEBBINGTON et al., 2008). Abramovay (2000) aponta que a ruralidade deve ser compreendida como um "valor" da sociedade contemporânea e não como uma etapa a ser superada.

Em suma, o quadro a seguir sintetiza as principais contribuições da literatura apresentadas neste artigo.

(continua)

Quadro 1 Síntese das contribuições dos principais autores abordados no estudo

\begin{tabular}{|l|l|l|}
\hline \multicolumn{1}{|c|}{ Teóricos } & $\begin{array}{l}\text { Contribuição sobre Desenvolvimento } \\
\text { Rural }\end{array}$ & \multicolumn{1}{c|}{$\begin{array}{c}\text { Contribuição sobre Segurança } \\
\text { Alimentar }\end{array}$} \\
\hline $\begin{array}{l}\text { José F. } \\
\text { Graziano da } \\
\text { Silva }\end{array}$ & $\begin{array}{l}\text { - Descreve a aproximação e as novas } \\
\text { relações do rural com o urbano como } \\
\text { caracterizadoras do novo rural } \\
\text { brasileiro. }\end{array}$ & $\begin{array}{l}\text { estruturantes para a segurança } \\
\text { alimentar, visando, além do alimento, } \\
\text { garantir à população direitos básicos. }\end{array}$ \\
\hline
\end{tabular}


(continuação)

\begin{tabular}{|c|c|c|}
\hline $\begin{array}{l}\text { Ângela } \\
\text { Kageyama }\end{array}$ & $\begin{array}{l}\text { - A promoção do desenvolvimento } \\
\text { rural a partir de uma visão territorial; } \\
\text { - Destaca a crescente participação de } \\
\text { rendas não agrícolas no meio rural. }\end{array}$ & $\begin{array}{l}\text { - Aborda os fatores que determinam a } \\
\text { desigualdade de renda no Brasil e o } \\
\text { impacto dessa na segurança alimentar } \\
\text { da população. }\end{array}$ \\
\hline Walter Belik & $\begin{array}{l}\text { - Interação entre os agentes } \\
\text { econômicos do campo com o } \\
\text { Estado, visando corrigir falhas de } \\
\text { mercado. }\end{array}$ & $\begin{array}{l}\text { - Analisa a política pública como } \\
\text { criador do ambiente institucional } \\
\text { favorável à segurança alimentar, } \\
\text { fomentado, sobretudo, por políticas } \\
\text { públicas, a exemplo do Fome Zero. }\end{array}$ \\
\hline $\begin{array}{l}\text { Sérgio } \\
\text { Schneider }\end{array}$ & $\begin{array}{l}\text { - Processo multifacetado envolvendo } \\
\text { uma ampliação do espaço rural às } \\
\text { atividades agropecuárias; } \\
\text { - Aspecto multidimensional da } \\
\text { sustentabilidade do desenvolvimento; } \\
\text { - Dinamização do papel da } \\
\text { agricultura familiar; } \\
\text { - Combate à pobreza e às múltiplas } \\
\text { vulnerabilidades das populações } \\
\text { rurais. }\end{array}$ & $\begin{array}{l}\text { - Destaca o papel da agricultura } \\
\text { familiar como produtora de gêneros } \\
\text { alimentícios; } \\
\text { - Atenta para a necessidade de } \\
\text { sinergia entre os agricultores e o } \\
\text { Estado, destacando suas políticas para } \\
\text { o meio rural. }\end{array}$ \\
\hline Eliseu Alves & $\begin{array}{l}\text { - Enfatiza a agricultura familiar com } \\
\text { o uso de recursos tecnológicos; } \\
\text { - Destaca a importância de medidas } \\
\text { institucionais para o } \\
\text { desenvolvimento da agricultura } \\
\text { familiar. }\end{array}$ & $\begin{array}{l}\text { - Aponta a agricultura familiar como } \\
\text { um agente essencial para a produção } \\
\text { de alimentos no país. }\end{array}$ \\
\hline $\begin{array}{l}\text { Arilson da } \\
\text { Silva } \\
\text { Favareto }\end{array}$ & $\begin{array}{l}\text { - Afirma que o desenvolvimento } \\
\text { rural deve ser analisado sob a ótica } \\
\text { territorial, considerando as diferentes } \\
\text { realidades e culturas existentes no } \\
\text { país. }\end{array}$ & $\begin{array}{l}\text { - A identificação das especificidades } \\
\text { locacionais permite o incentivo às } \\
\text { atividades comparativamente mais } \\
\text { eficientes, o que eleva a renda no } \\
\text { campo ampliando o acesso aos bens e } \\
\text { serviços essenciais. }\end{array}$ \\
\hline $\begin{array}{l}\text { Rodolfo } \\
\text { Hoffmann }\end{array}$ & $\begin{array}{l}\text { - A pobreza no mundo rural é a } \\
\text { principal causa do atraso do setor } \\
\text { rural; } \\
\text { - Concentração da propriedade } \\
\text { fundiária e de renda no país. }\end{array}$ & $\begin{array}{l}\text { - A produção de alimentos supera as } \\
\text { necessidades de sustento da } \\
\text { população do país, a baixa renda per } \\
\text { capita é o principal determinante da } \\
\text { carência de alimentos nos domicílios } \\
\text { brasileiros. }\end{array}$ \\
\hline
\end{tabular}


(conclusão)

\begin{tabular}{|l|l|l|}
\hline $\begin{array}{l}\text { Renato } \\
\text { Maluf }\end{array}$ & $\begin{array}{l}\text { - O desenvolvimento rural se dá } \\
\text { através da implantação de políticas } \\
\text { públicas que possam, principalmente, } \\
\text { fortalecer a agricultura familiar. }\end{array}$ & $\begin{array}{l}\text { - Enfatiza que a segurança alimentar é } \\
\text { um componente estratégico do } \\
\text { padrão de desenvolvimento de uma } \\
\text { nação. }\end{array}$ \\
\hline $\begin{array}{l}\text { José Eli da } \\
\text { Veiga }\end{array}$ & $\begin{array}{l}\text { - O desenvolvimento rural é parte do } \\
\text { processo dinâmico de } \\
\text { desenvolvimento da nação; } \\
\text { - Deve estar associado à preservação } \\
\text { ambiental e sustentabilidade. }\end{array}$ & $\begin{array}{l}\text { - Propõe a revisão e re-estimação da } \\
\text { definição do meio rural no Brasil; } \\
\text { - Gerar, no meio rural, oportunidades } \\
\text { de renda não agrícolas. }\end{array}$ \\
\hline $\begin{array}{l}\text { Ricardo } \\
\text { Abramovay }\end{array}$ & $\begin{array}{l}\text { - Considera a organização regional } \\
\text { como fator dinamizador de um } \\
\text { projeto de desenvolvimento } \\
\text { territorial e não apenas programas } \\
\text { setoriais. }\end{array}$ & $\begin{array}{l}\text { - Organização territorial mais efetiva } \\
\text { propicia ganhos de eficiência à } \\
\text { produção agropecuária e possibilita a } \\
\text { identificação de vantagens locais com } \\
\text { o objetivo de incrementar a renda da } \\
\text { população do campo. }\end{array}$ \\
\hline
\end{tabular}

Fonte: Elaborado pelos autores.

Conforme exposto ao longo desse artigo, as ações desenvolvidas no âmbito de políticas públicas nacional e as contribuições científicas dos pesquisadores brasileiros acerca da temática de erradicação da fome e promoção de um patamar digno de bem-estar social assentam-se em dois componentes básicos: o componente alimentar, relacionado à produção, disponibilidade, comercialização e acesso ao alimento; e o componente nutricional, relacionado às práticas alimentares e à utilização biológica do alimento, e, portanto, ao estado de nutrição da população.

Em adição, percebe-se que as ações públicas e as contribuições teóricas discutidas propõem um modelo de produção e consumo de alimentos mais sustentável, que aproxime a produção de pequenos agricultores familiares e o consumo de alimentos, contribuindo para a reconexão da cadeia alimentar e de uma relação mais estreita entre campo e cidade, além de promover o desenvolvimento territorial rural.

\section{Considerações finais}

Este artigo teve como objetivo central realizar uma abordagem dos principais pensadores sobre a economia rural brasileira com ênfase na segurança alimentar, a 
fim de contextualizar o ambiente institucional do qual evoluiu a discussão sobre a segurança alimentar e o desenvolvimento rural brasileiro.

Como corolário, no período analisado (1964-2011), o país passou por diversas transformações, a exemplo da expansão do sistema rodoviário, política de crédito rural e de garantias de preços mínimos, bem como políticas de apoio à pesquisa e extensão rural. Além disso, as relações dinâmicas entre as atividades agrícolas e industriais permitiram, ainda na década de 1970, a expansão da oferta de alimentos.

Em relação à segurança alimentar, este estudo evidenciou que a discussão é recente. A conotação de segurança alimentar abordada neste artigo baseou-se na garantia da condição de acesso suficiente, regular e a baixo custo de alimentos para toda a população e evidenciou-se que as medidas direcionadas à garantia da segurança alimentar devem combinar ações assistenciais e emergenciais de combate a fome, a partir de políticas com caráter estruturante, visando assegurar o acesso aos alimentos, sem comprometer parcela substancial da renda familiar.

Fundamentado nos autores apresentados neste estudo, percebeu-se que as políticas agrícolas e estruturantes adotadas no Brasil contribuíram para fomentar a segurança alimentar, nutricional e a equidade social, bem como, permitiram a ampliação da discussão sobre o desenvolvimento rural. Todavia, sabe-se que alcançar uma seguridade alimentar e nutricional plena é um processo longo e multifuncional, ainda existem diversos critérios a serem atendidos e ações a serem planejadas e aplicadas para a erradicação da fome no Brasil e o alcance de uma íntegra seguridade nutricional.

Em específico, no que se refere ao desenvolvimento rural, percebeu-se que se trata de um processo complexo e em permanente evolução, ora evoluindo de forma lenta, ora através de mudanças abruptas. Nessa dinâmica destaca-se o que os estudiosos denotam de novo rural, que combina tanto a visão agrícola e produtivista, como a visão territorial por meio da exploração de especificidades locais.

O novo rural é apresentado como uma alternativa para o desenvolvimento e a solidificação de pequenos agricultores e, consequentemente, para o alcance da condição de segurança alimentar por meio da agricultura familiar. Essa, por sua vez, é viabilizada por meio da elevação da renda, garantia de direitos mínimos e, ainda, pelos incrementos comerciais obtidos pela maior aproximação da produção de alimentos em relação aos grandes centros urbanos. Conforme comentado, o novo rural, que é marcado pelo não rural, recebe fortes influências do urbano; no entanto, a produção de alimentos ainda continua sendo rural.

Deste modo, o desenvolvimento rural deve ser considerado a partir das relações entre agricultura e sociedade como novo modelo para o setor agrícola, com particular atenção ao local e ao regional e, como novas formas de alocação do trabalho familiar, especialmente a pluriatividade. Pode-se considerar ainda que o 
desenvolvimento rural deve combinar o aspecto econômico, por meio do aumento do nível e estabilidade da renda familiar, e o aspecto social, mediante a obtenção de um nível de vida socialmente aceitável, e que sua trajetória principal possa residir na diversificação das atividades que geram renda e bem-estar a toda população rural.

Por fim, destaca-se que este artigo não teve a pretensão de esgotar o assunto abordado e sugere novos estudos para a comparação das políticas públicas brasileiras relacionadas à segurança alimentar com as de outros países da América Latina, bem como a sua relação com o desenvolvimento regional e o local.

\section{Referências}

ABRAMOVAY, R. O capital social dos territórios: repensando o desenvolvimento rural. Economia Aplicada, São Paulo, n. 2, v. IV, p. 379-397, 2000 .

ABRAMOVAY, R.; BEDUSCHI FILHO, L. C. Desafios para o desenvolvimento das regiões rurais. Nova Economia, UFMG, Belo Horizonte, v. 14, n.3, p. 35-70, 2004.

ALVES, E. Agricultura familiar prioridade da Embrapa. Brasília: Embrapa Informação Tecnológica, 2001. p 55.

Agricultura familiar. Revista de Política Agrícola, ano XV n. 4, p. 3, out.-dez., 2006.

ALVES, E.; SOUZA, G. S.; OLIVEIRA, C. A. V. Desempenho de estabelecimentos do Pronaf. Revista de Política Agrícola, ano XV, n. 4, p. 5-23, out./nov./dez., 2006.

BACHA, C. J. C. Economia e política agrícola no Brasil. São Paulo: Atlas, 2012.

BEBBINGTON, A.; ABRAMOVAY, R.; CHIRIBOGA, M. Social movements and the dynamics of rural territorial development in Latin America. World Development, v. 36, p. 2874-2887, 2008.

BELIK, W. PRONAF: avaliação da operacionalização do programa. Campinas, SP: Universidade Estadual de Campinas - NEA, 1999. 
- Perspectivas para segurança alimentar e nutricional no Brasil. Saúde e Sociedade, v. 12, n. 1, p. 12-20, jan.-jun., 2003.

A Política Brasileira de Segurança Alimentar e Nutricional: concepção e resultados. Segurança Alimentar e Nutricional, Campinas, 19(2), p. 94-110, 2012.

BOSI, M. L. M. Desafios na interface pesquisa-construção do direito humano à alimentação: reflexões no âmbito da segurança alimentar e nutricional. Ciência e Saúde Coletiva, v. 15, n. 1, p. 19-30, 2010.

CHADDAD, F. R.; JANK, M. S. The evolution of agricultural policies and agribusiness development in Brazil. Choices Magazine, v. 21, n. 2, p. 85-90, 2006.

FAVARETO, A. S. et al. Políticas de desenvolvimento territorial rural no Brasil: avanços e desafios. Brasília: IICA, 2010. (Série Desenvolvimento Rural Sustentável; v. 12) 220 p.

. La nueva ruralidad brasileña: lo que cambió (y lo que no cambió) en el ámbito rural. Revista Nueva Sociedad, n. 223, p. 146-16, set./out., 2009.

FLICK, U. Desenho da pesquisa qualitativa. Porto Alegre: Artmed, 2009.

FURTADO, C. Formação Econômica do Brasil. 34. ed. São Paulo: Cia. das Letras, 2007.

GASQUES, J. G. et al. Produtividade total dos fatores e transformações da agricultura brasileira: análise dos dados dos censos agropecuários. In: GASQUES, J. G.; VIEIRA FILHO, J. E. R.; NAVARRO, Z. (Org.). A agricultura brasileira: desempenho, desafios e perspectivas. Brasília: IPEA, 2010.

GRAZIANO DA SILVA, J. F. (Coord.). Estudos de caso para avaliação dos impactos do PRONAF. Campinas, 2002.

Velhos e novos mitos do rural brasileiro: implicações para as políticas públicas. Reforma Agrária, Brasília, v. 31, n. 1, p. 31-45, 2002.

O novo rural brasileiro. Campinas: UNICAMP/IE, 1999. 
GRAZIANO DA SILVA, J. F.; BELIK, W.; TAKAGI, M. To the critic soft he Zero Hunger Program. In: GRAZIANO DA SILVA, J.; DEL GROSSI, M. E.; FRANÇA, C. G. de (Orgs.) The Fome Zero (Zero Hunger) Program: The Brazilian experience. Brasília: MDA, 2010.

HOFFMANN, R. Transferências de renda e a redução da desigualdade no Brasil e cinco regiões entre 1997 e 2004. Econômica (Niterói), v. 8, p. 55-81, 2006.

. Determinantes da insegurança alimentar no Brasil: análise dos dados da PNAD de 2004. Segurança Alimentar e Nutricional, v. 15, p. 49-61, 2008.

- Pobreza, insegurança alimentar e desnutrição no Brasil. Estudos Avançados, São Paulo/SP, v. 9, n. 24, p. 159-172, 1995.

HOFFMANN, R.; KAGEYAMA, A. Pobreza, insegurança alimentar e pluriatividade no Brasil. Teoria e Evidência Econômica, v. 14, p. 9-35, 2007.

IBGE. Instituto Brasileiro de Geografia e Estatística. Banco de dados agregados SIDRA. Disponível em: http://www.sidra.ibge.gov.br/bda. Acesso em: 10 out. 2013.

JANK, M. S.; NASSAR, A. M.; TACHINARDI, M. T. Agronegócio e comércio exterior. Revista USP, São Paulo, n. 64, p. 14-27, 2005.

KAGEYAMA, A. O novo padrão agrícola brasileiro: do complexo rural aos complexos agroindustriais. In: DELGADO; Guilherme C. (Org.). Agricultura e Políticas Públicas. Brasília/DF: IPEA, v. 1, p. 113-223, 1990.

A pluriatividade na agricultura paulista. Revista de Economia e Sociologia Rural, Brasília, v. 37, n. 1, p. 35-56, 1999.

As múltiplas fontes de renda das famílias agrícolas brasileiras. Agricultura em São Paulo, São Paulo, v. 48, n. 2, p. 57-69, 2001.

- Produtividade e renda na agricultura familiar: efeitos do Pronaf - crédito. Agricultura em São Paulo, São Paulo, v. 50, n.2, p. 1-13, 2003 a.

. Os rurais e os agrícolas de São Paulo no Censo de 2000. Cadernos de Ciência e Tecnologia, Brasília/DF, v. 20, n. 3, p. 413-451, set./dez. 2003b.

Desenvolvimento rural: conceitos e medidas. Cadernos de Ciência e Tecnologia, v. 21, n. 3, set./dez., p. 379-408, 2004. 
Desenvolvimento rural: conceitos e aplicação ao caso brasileiro. Porto Alegre: UFRGS, 2008.

KAGEYAMA, A.; HOFFMANN, R. Determinantes da renda e condições de vida das famílias agrícolas no Brasil. Economia, Rio de Janeiro, v. 1, n. 2, p. 147-183, jul./dez., 2000.

KAGEYAMA, A.; LEONE, E. T. Trajetórias da modernização e emprego agrícola: Brasil, 1985-1996. Revista de Economia e Sociologia Rural, Brasília, v. 40 , n. 1, p. 9-28, 2002.

KAGEYAMA, A.; SILVA, J. G. Os resultados da modernização agrícola dos anos 70. Estudos Econômicos, IPE, São Paulo/SP, v. 13, n. 3, p. 537-559, 1983.

LAFER, C. A ONU e os direitos humanos. Estudos Avançados. São Paulo, v. 9, n. 25, dez., 1995.

MALUF, R. S. Segurança alimentar e desenvolvimento econômico na América Latina: o caso Brasil. Revista de Economia Política, v. 15, n. 1 (57), p. 134-140, jan./mar., 1995.

Ações Públicas Locais de Apoio à Produção de Alimentos e à Segurança Alimentar. Revista Pólis Papers, v. 4, 1999.

Consumo de Alimentos no Brasil: traços gerais e ações públicas locais de segurança alimentar. Revista Pólis Papers, v. 6, 2000.

A multifuncionalidade da agricultura na realidade rural brasileira. In: CARNEIRO, M. J.; MALUF, R. (Org.) Para além da produção: multifuncionalidade e agricultura familiar. Rio de Janeiro: Mauad, p. 135-152, 2003.

MALUF, R. S.; MENEZES, F.; VALENTE, F. L. Contribuição ao tema da segurança alimentar no Brasil. Revista Caderno de Debates, p. 66-88, 1996.

MONTEIRO, C. A.; CASTRO, I. R. R. de. Por que é necessário regulamentar a publicidade de alimentos. Ciência e cultura, v. 61, n. 4, p. 56-58, 2009.

NAVARRO, Z. Desenvolvimento rural brasileiro: os limites do passado e os caminhos do Futuro. Estudos Avançados, 15 (43), p. 83-100, 2001. 
A Agricultura Familiar no Brasil: entre a política e as transformações da vida econômica. In: GASQUES, J. G.; VIEIRA, J. E. R.; NAVARRO, Z. (Org.). A agricultura brasileira: desempenho, desafios e perspectivas. Brasília: IPEA, 2010 .

NORDER, L. A. C. A construção da segurança alimentar em assentamentos rurais: questões, contextos e métodos. Revista Cadernos de Debate, Núcleo de Estudos e Pesquisas em Alimentação da UNICAMP, p. 40-58, v. VI, 1998.

PAIVA, R. M. Setor agrícola do Brasil: comportamento econômico, problemas e possibilidades. Rio de Janeiro: Forense-Universitária, 2. ed. 1976.

PEREIRA, P. A. A. et al. The development of Brazilian agriculture, future technological challenges and opportunities. In: MARTHA JUNIOR, G. B.; FERREIRA FILHO, J. B. de (Ed.) Brazilian agriculture development and changes. Brasília, DF: Embrapa, p. 13-42, 2012.

RICHARDSON, R. J. Pesquisa social: métodos e técnicas. 2. ed. São Paulo: Atlas, 2007.

ROCHA, Marlene da. Segurança alimentar: um desafio para acabar com a fome no Brasil. 1. ed. São Paulo: Editora Fundação Perseu Abramo (Coleção Cadernos da Fundação Perseu Abramo), 2004.

SCHNEIDER, S. O Desenvolvimento Agrícola e as Transformações da Estrutura Agrária nos Países Desenvolvidos: a pluriatividade. Revista Reforma Agraria, ABRA, Campinas, v. 24, n. 3, p.106-132, 1994.

A agricultura familiar em uma época de transformações: a pluriatividade como estratégia familiar de reprodução social. In: World Congress of Rural Sociology, 10. Anais... Rio de Janeiro: IRSA, jul. 2000.

A abordagem territorial do desenvolvimento rural e suas articulações externas. Sociologias, Porto Alegre, v. 11, p. 88-125, 2004.

. Situando o desenvolvimento rural no Brasil: o contexto e as questões em debate. Revista de Economia Política, v. 30, p. 511-531, 2010.

SCHNEIDER, S.; BLUME, R. Ensaio para uma abordagem territorial da ruralidade: em busca de uma metodologia. Revista Paranaense de Desenvolvimento, Curitiba-Paraná, v. 107, p. 109-135, 2004. 
SCHNEIDER, S.; SHIKI, S.; BELIK, W. Rural Development in Brazil: overcoming inequalities and building new markets. Rivista di Economia Agraria, LXV, p. 226-259, 2011.

SZMRECSÁNYI, T. J. M. K. Pequena história da agricultura brasileira. São Paulo: Hucitec, 1997.

SZMRECSÁNYI, T. J. M. K.; RAMOS, P. O Papel das Políticas Governamentais na Modernização da Agricultura Brasileira. História \& Perspectivas, n. 10, p. 5979, 1996.

TAKAGI, M. A Implantação da política de segurança alimentar e nutricional no Brasil: seus limites e desafios. Tese (Doutorado em Economia) Programa de Pós-Graduação em Economia, Universidade Estadual de Campinas Unicamp, Campinas, 2006.

VASCONCELOS, M. A. S.; GREMAUD, A. P.; TONETO JUNIOR, R. Economia Brasileira Contemporânea. 3. ed. São Paulo: Atlas, v. 1, 371 p., 1999.

VEIGA, J. E. Política agrícola diferenciada. In: TEIXEIRA, Erly Cardoso; VIEIRA, Wilson da Cruz (Org.). Reforma da política agrícola e abertura econômica. 1. ed. Viçosa/MG: IFV-Fapemig, 1996

A face rural do desenvolvimento: natureza, território e agricultura. Porto Alegre: Editora da UFRGS, 2000.

- Do crescimento Agrícola ao Desenvolvimento Rural. In: Ana Celia Castro (Org.). Desenvolvimento em Debate. 1. ed. Rio de Janeiro, RJ: MauadBNDES, 2002, v. 3, p. 383-409.

2006.

. Nascimento de outra ruralidade. Estudos Avançados, v. 20, p. 333-353, 
Endereço para correspondência:

UdoStrassburg-udo@udostrassburg.com.br

Rua Universitária, 2069

85.819-110 Cascavel/PR, Brasil

Nilton Marques de Oliveira - niltonmarques@uft.edu.br Rua da Faculdade, 645, Jardim Santa Maria 85.903-000 Toledo/PR, Brasil

Isabela Barchet - isabelabarchet@hotmail.com

Rua Universitária, 2069

85.819-110 Cascavel/PR, Brasil

Camili Dal Pai - camili.dpp@gmail.com

Av. José Monteiro de Figueiredo, Duque de Caias I 78.043-300 Cuiabá/MT, Brasil

Paulo César da Silva Ilha - paulocesarilha@yahoo.com.br Rua Universitária, 2069

85.819-110 Brasília/DF, Brasil

Pery Francisco Assis Shikida - peryshikida@hotmail.com Rua da Faculdade, 645, Jardim Santa Maria 85.903-000 Toledo/PR, Brasil 